九州大学学術情報リポジトリ

Kyushu University Institutional Repository

\title{
Design and Preparation of Succinic Acid-Based Metal-Organic Frameworks for CO_2 Adsorption Technology
}

Yulia, Fayza

Department of Mechanical Engineering, Faculty of Engineering, Universitas Indonesia

Marsya, Shavira

Department of Mechanical Engineering, Faculty of Engineering, Universitas Indonesia

Bobby, Yohanes

Department of Mechanical Engineering, Faculty of Engineering, Universitas Indonesia

Nasrudd in

Department of Mechanical Engineering, Faculty of Engineering, Universitas Indonesia

他

https://doi.org/10.5109/4150475

出版情報：Evergreen. 7 (4)，pp.549-554，2020-12. 九州大学グリーンテクノロジー研究教育センター バージョン：

権利関係 : 


\title{
Design and Preparation of Succinic Acid-Based Metal-Organic Frameworks for $\mathrm{CO}_{2}$ Adsorption Technology
}

\author{
Fayza Yulia ${ }^{1}$, Shavira Marsya ${ }^{1}$, Yohanes Bobby ${ }^{1}$, Nasruddin $^{1, *}$, and A Zulys ${ }^{2}$ \\ ${ }^{1}$ Department of Mechanical Engineering, Faculty of Engineering, Universitas Indonesia, \\ Depok, 16424, Indonesia \\ ${ }^{2}$ Department of Chemistry, Faculty of Mathematics and Natural Sciences, Universitas Indonesia, \\ Depok, 16424, Indonesia
}

*Corresponding Author’s email: nasruddin@eng.ui.ac.id

(Received November 4, 2020; Revised December 9, 2020; accepted December 16, 2020).

\begin{abstract}
Increasing amount of $\mathrm{CO}_{2}$ in the atmosphere caused by human activities has quickly become one of the most urgent environmental issues. $\mathrm{CO}_{2}$ Capture and Storage (CCS) is a promising option as it can reduce the amount of $\mathrm{CO}_{2}$ emissions in the atmosphere. It is critical to develop an efficient separation technique for capturing $\mathrm{CO}_{2}$ from the gas streams. One of the technologies in CCS is utilizing a crystalline porous material called Metal-Organic Frameworks (MOFs). To take the advantages of MOF due to the ease of modification, we designed bio related ligand from natural products in the form of porous framework. Bio-MOFs discussed in this research is made from Chromium (III) Nitrate and Succinic Acid $\left(\mathrm{C}_{4} \mathrm{H}_{6} \mathrm{O}_{4}\right)$ as ligand. The synthesis is carried out through hydrothermal reaction method using water as solvent. This research measured Chromium-Succinate MOF's porous properties, thermal stability, morphology, and chemical functionalities by performing various test such as adsorption/desorption of $\mathrm{N}_{2}$, thermogravimetric analysis (TGA), scanning electron microscope (SEM), and Fourier Transform Infrared Spectroscopy (FTIR) analysis. The results of this study show that this Bio-MOF based succinic acid (Cr-SA) has surface area of 233 $\mathrm{m}^{2} / \mathrm{g}$ with pore volume of $0.66 \mathrm{~cm}^{3} / \mathrm{g}$. The porosity of Bio-MOF Cr-SA is comparable to other reported Bio-MOFs. Bio-MOF Cr-SA also has good thermal stability which can maintain its structure up to temperatures above $350^{\circ} \mathrm{C}$. From the Bio-MOF properties that have been investigated, it is expected that it would be a preliminary study for the use of succinic acid bio-ligands in MOF for $\mathrm{CO}_{2}$ capture application.
\end{abstract}

Keywords: Bio-MOFs; $\mathrm{CO}_{2}$ uptakes; Adsorbent Characteristics; Adsorption; Succinic Acid

\section{Introduction}

The emissions of Carbon Dioxide from burning fossil fuel have reached such an alarming rate, resulting in worldwide impact, the need for an effective method for reducing the amount of $\mathrm{CO}_{2}$ emission has never been this high ${ }^{1,2)}$. In 2011, globally averaged atmospheric $\mathrm{CO}_{2}$ at Earth's surface reached 390.4 ppm surpassing 390 ppm limit for the first time. This means the global atmospheric $\mathrm{CO}_{2}$ level has risen more than $110 \mathrm{ppm}$ compared when the industrial age begun at $1750^{3)}$. Most of the $\mathrm{CO}_{2}$ emission is caused by anthropogenic activities such as electricity generation that takes up $26 \%$ of total $\mathrm{CO}_{2}$ emissions and road transport field which accounts for around $25 \%$ of $\mathrm{CO}_{2}$ emissions ${ }^{4}$. Therefore, global $\mathrm{CO}_{2}$ emissions can be drastically reduced by preventing the amount of $\mathrm{CO}_{2}$ released by chemical reaction in power plants and mobile transportation into the atmosphere ${ }^{5)}$. Many researches have been focusing on finding suitable method for specifically lowering the $\mathrm{CO}_{2}$ released by burning fossil fuel; and one of which is Carbon Capture and Storage $(\mathrm{CCS})^{6}$. CCS has been estimated to reduce $80 \%-90 \% \mathrm{CO}_{2}$ emission in power plant equipped with suitable CCS technologies ${ }^{5)}$. Generally, based on the fundamental chemical process involved in the combustion of fossil fuels, there are three basic $\mathrm{CO}_{2}$ separation and capture method: (1) pre-combustion capture; (2) oxy-fuel combustion; and (3) post-combustion capture ${ }^{7)}$. This research is focusing on post-combustion capture by removing $\mathrm{CO}_{2}$ from flue gas. This method is the most feasible on short-time scale and research in this area has future benefit on developing application in natural gas ${ }^{8,9)}$. One of the challenges of this method is finding the suitable material that has exact property, so that the $\mathrm{CO}_{2}$ capturing process has high performance while still being costefficient and suitable for long-term use.

Adsorption process in CCS can be done using either chemical sorbent which involve the interaction between 
chemicals which lead to the formation of molecular structures that are $\mathrm{CO}_{2}$-based, or physical sorbent that rely on porous material to form the bond between sorbent and sorbate $^{10)}$. Chemical sorbent consumes relatively higher energy compared to when using physical sorbent making it less-reliable at the moment; thus, most researches tend to focus on carbon capture by physical adsorption by considering materials and experimental investigations ${ }^{9}$. Moreover, in the few past decades, the development a material called Metal Organic Frameworks (MOF) has become hot topic in the field of material science ${ }^{9)}$. MOFs are known for its high-porosity, adjustable pore, excellent sensitivity and adsorbing ability, making it suitable adsorbent in CCS application ${ }^{11,12)}$. Implementation of MOF-based CCS in post-combustion system is to limit the amount of $\mathrm{CO}_{2}$ released to atmosphere. The goal is to create MOF that has high performance of separation, environmentally friendly, and cost-effective technologies. The green chemistry priority including renewability and recyclability cannot be achieved with the use of commercial MOF where most of the material comes from petrochemical feedstock. Biological MOF, known as Bio$\mathrm{MOF}$, can be a solution as it has green composition, costeffectiveness, and recyclability ${ }^{13)}$.

Bio-MOF uses ligand that is taken from natural sources and mostly found in living organism such as amino acids, peptides, nucleobases and saccharides ${ }^{14,15)}$. These ligands come with various shape and size that offer the potential to utilize multiple coordination sites and functional group. They also can be useful in controlling hydrogen-bond and creating flexible and robust MOF structure. Bio-ligand offers opportunity for researcher to create various combination based on chirality, aromaticity, cyclic or aliphatic features that they desired ${ }^{14)}$. This advantage makes Bio-MOF a promising solution for $\mathrm{CO}_{2}$ capture, separation, photoluminescent, and catalyst ${ }^{14)}$.

Utilizing multidentate $\mathrm{N}$ - or $\mathrm{O}$ - donor ligand and multifunctional carboxylic acid in the formation of MOF structures had been widely used to increase the gas adsorption performance ${ }^{16)}$. Succinic Acid (SA) is a natural acid that is commonly found in foods such as vegetables and fruits with an affordable price ${ }^{17}$. This carboxylic acid groups have interesting behavior due to the conformational flexibility, coordination diversity, and attracting the $\mathrm{CO}_{2}$ molecules. The SA ligand design with the lanthanide group had also been investigated ${ }^{18-21)}$. However, the MOF design of SA and transition metal are still less explored.

To demonstrate its feasibility as a ligand on MOF for transition metals, we performed a synthesis using the hydrothermal method of Bio-MOF based on metal ion Chromium (Cr) and Succinic Acid. Their high affinity and chemical structure that can be used to make an excellent MOF in term of porosity and coordination chemical bond will determine the adsorbing quality of the product for gas adsorption application. Herein, we report the new topology of Bio-MOF Cr-SA which is equipped with adsorbent physical characteristics such as structure, porosity, thermal stability, chemical functionalities and morphology. It is expected that in the future, this research can become the guidance in the use of natural succinic acid ligands with transition metals for $\mathrm{CO}_{2}$ capture applications.

\section{Methodology}

\subsection{Materials}

Chrome(iii)Nitrate and Succinic acid used in this experiment were purchased from Aldrich Chemical Co. Inc. and used as received. Other materials needed for performing this experiment are sodium sulphate, $\mathrm{NaOH}$, N,N-dimethylformamide (DMF) from Merck, demineralized water and Ethanol where those chemicals are widely available in market.

\subsection{Synthesis Procedure}

The Synthesis of Chromium-Succinate MOF is done using hydrothermal method as illustrated in Fig. ${ }^{20)}$. The procedure begins by dissolving $0.46 \mathrm{~g}$ of Chromium Nitrate in $30 \mathrm{~mL}$ water then reacting the solution with 0.13 g Succinic Acid and 0.008 g Sodium Sulphate. Sodium Hydroxide is then added until the $\mathrm{pH}$ of the solution is 5.0. Solution is then placed inside autoclave to be heated in the oven for 18 hours at $160^{\circ} \mathrm{C}$. Furthermore, the autoclave is cooled to room temperature. After cooling, DMF is dropped on the sample to remove the unreacted substance, then the sample is heated at $80^{\circ} \mathrm{C}$ for 5 hours $^{22)}$. Afterwards the MOF is separated from the solution using centrifugation. In the sample that has been formed, MOF is then dropped by ethanol to then be heated at $80^{\circ} \mathrm{C}$ for 5 hours to eliminate the remaining DMF in the pores. Finally, drying process is carried out for 12 hours at $80^{\circ} \mathrm{C}$. After drying process is complete, the sample is ready for characterization.

\subsection{Adsorbent Characterization}

Characterization is done using various tests by referring to literature ${ }^{22)}$. The presence of functional group is tested using Spectrophotometer FTIR (Fourier Transform InfraRed). The method is carried out on $\mathrm{KBr}$ using Thermo Scientific $^{\mathrm{TM}}$ Nicolet $^{\mathrm{TM}}$ iS $^{\mathrm{TM}} 5$. The thermal stability is analyzed by the TGA Q500 instrument. The sample is heated to a temperature of $550^{\circ} \mathrm{C}$ with a heating rate of $10^{\circ} \mathrm{C} / \mathrm{min}$ below the flow of oxygen. Morphology, microstructure, and particle size are measured using SEM (Scanning Electron Microscopy) by JEOL FESEM at a voltage of $20 \mathrm{kV}$ and MOF's. $\mathrm{N}_{2}$ adsorption/desorption isotherm is measured in an ASAP-2020 adsorption apparatus (Micromeritics).

\section{Result and Discussion}

\subsection{Synthesis}


The synthesis process of succinic acid-based BioMOFs is carried out using the solvothermal method which refers to the synthesis of succinate-sulfate MOFs that had been carried out by D'Vries et $\mathrm{al}^{20)}$. Succinic acid organic compound used as a ligand with the metal used is chromium nitrate with a molar ratio of $1: 1$.

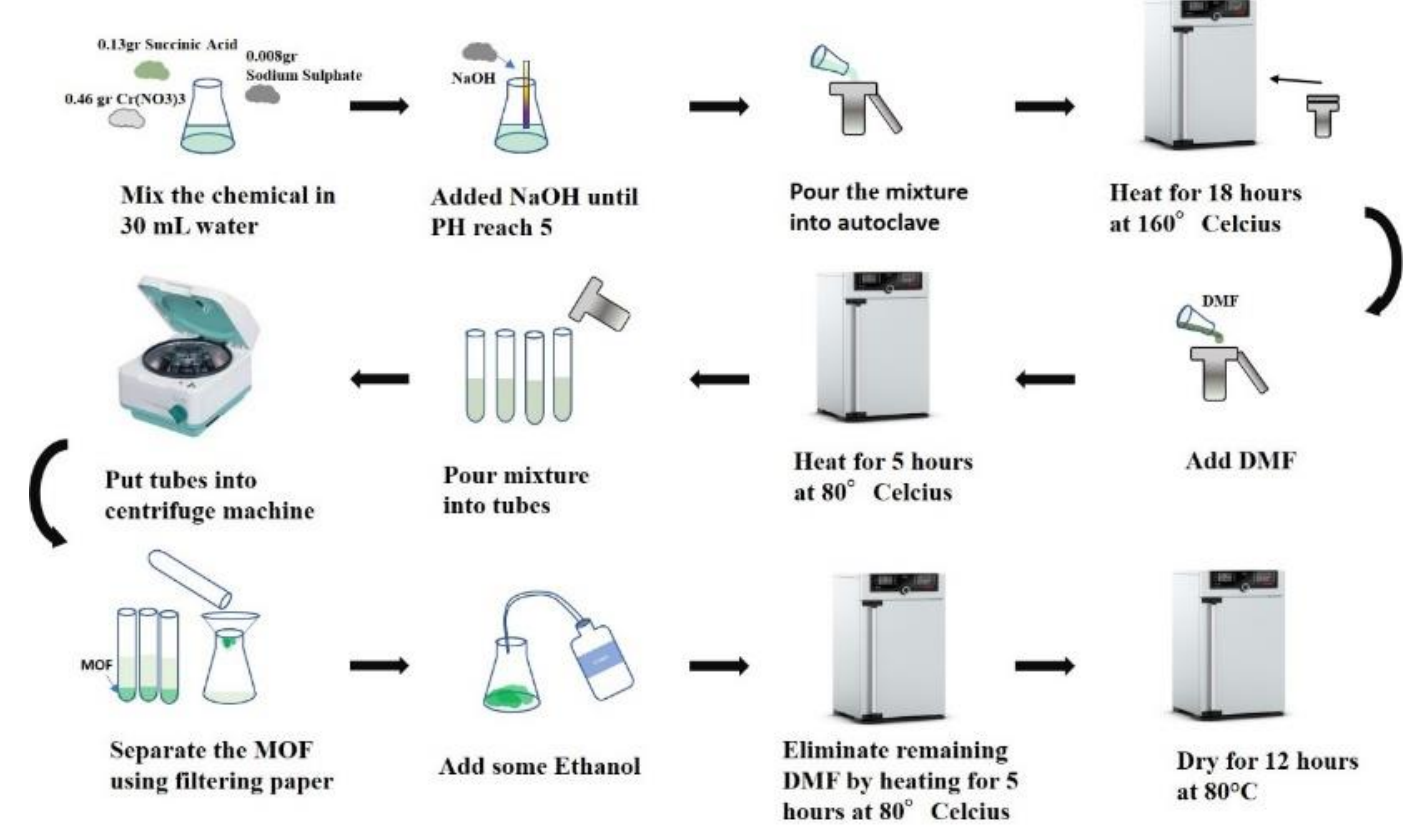

Fig. 1: Synthesis Procedure of Chromium-Succinate Bio-MOFs

The solvent used in the synthesis process affects the size of the MOF. $\mathrm{CO}_{2}$ molecules adsorbed involve the coordinative vacancies of $\mathrm{MOFs}^{23)}$. $\mathrm{NaOH}$ was used in this synthesis process to increase the $\mathrm{pH}$ to 5 . Purification method was carried out in two steps to remove succinic acid which does not react with DMF organic solvents and anhydrous ethanol, to obtain better porous Bio-MOFs crystals.

\subsection{FTIR Analysis}

To identify the functional groups contained in the synthesized Bio-MOFs Chromium-Succinate, FTIR analysis was performed. Fig. 2 shows the IR spectra of Chromium-Succinate. The peak at $\sim 3371 \mathrm{~cm}^{-1}$ can be identified as stretching $\mathrm{O}-\mathrm{H}$ vibrations from water coordination and no peak observed at $1600 \mathrm{~cm}^{-1}$ indicates that water adsorption on Bio-MOFs particle did not exist 24). The broad band at $\sim 1538 \mathrm{~cm}^{-1}$ was assigned to as $\mathrm{v}_{s}(\mathrm{OCO})$, the peak at $1307 \mathrm{~cm}^{-1}$ indicates that there was $\left.\mathrm{v}_{s}(\mathrm{OCO}) \operatorname{mode}{ }^{25}, 26\right)$. The stretching vibration of the symmetrical carboxylic $\mathrm{C}=\mathrm{O}$ group was also seen at the peak around $1437 \mathrm{~cm}^{-1}$ with medium intensity ${ }^{27)}$. Further, the bands at 1108 and $985 \mathrm{~cm}^{-1}$ were assigned to asymmetric and symmetric $\mathrm{C}-\mathrm{C}$ stretching vibrations respectively ${ }^{28)}$. The bands at 649 and $592 \mathrm{~cm}^{-1}$ were assigned as the bending and vibrations of $\mathrm{COO}^{-}$in FT-IR spectrum. The peaks that have been described have been in accordance with a study conducted by Bernini et al. by designing Holmium-Succinate $\mathrm{MOFs}^{29}$. It means that the
MOF that has been synthesized contained the chemical functionalities of the succinic acid ligand. Thus, MOF have been successfully formed.

\subsection{Surface Area and Porosity}

The specific surface area, pore volume, and diameter of the Bio-MOFs chromium-succinate were calculated using Surface Area Analyzer (SAA) with the Multipoint BET (Brunauer Emmett Teller) method of $\mathrm{N}_{2}$ adsorption/desorption isotherms at $77.4 \mathrm{~K}$. The calculated surface area obtained is $233 \mathrm{~m}^{2} / \mathrm{g}$.

The total pore volume of this adsorbent is $0.66 \mathrm{~cm}^{3} / \mathrm{g}$ at relative pressure $\left(\mathrm{P} / \mathrm{P}_{0}\right) 0.99$. The average diameter of synthesized Chromium Succinate is $16.98 \mathrm{~nm}$. Table 1 shows the surface area comparison of some Bio-MOF that had been synthesized. In addition, the table shows that Chromium-Succinate has a fairly good surface area of another reported Bio-MOF. It is expected that with a good surface area potential, it can adsorb more $\mathrm{CO}_{2}$ molecules ${ }^{30)}$.

\subsection{Thermal Stability}

A property key in MOF adsorbent is thermal stability which is influenced by divalent metal nature ${ }^{31)}$. Fig.3 shows the thermogravimetric curves of ChromiumSuccinate Bio-MOFs with weight loss ratio with heating process up to $550^{\circ} \mathrm{C}$. The decrease in the first stage was at temperature $100^{\circ} \mathrm{C}$ caused by the evaporation of water molecules from the pores of the adsorbent. Furthermore, 


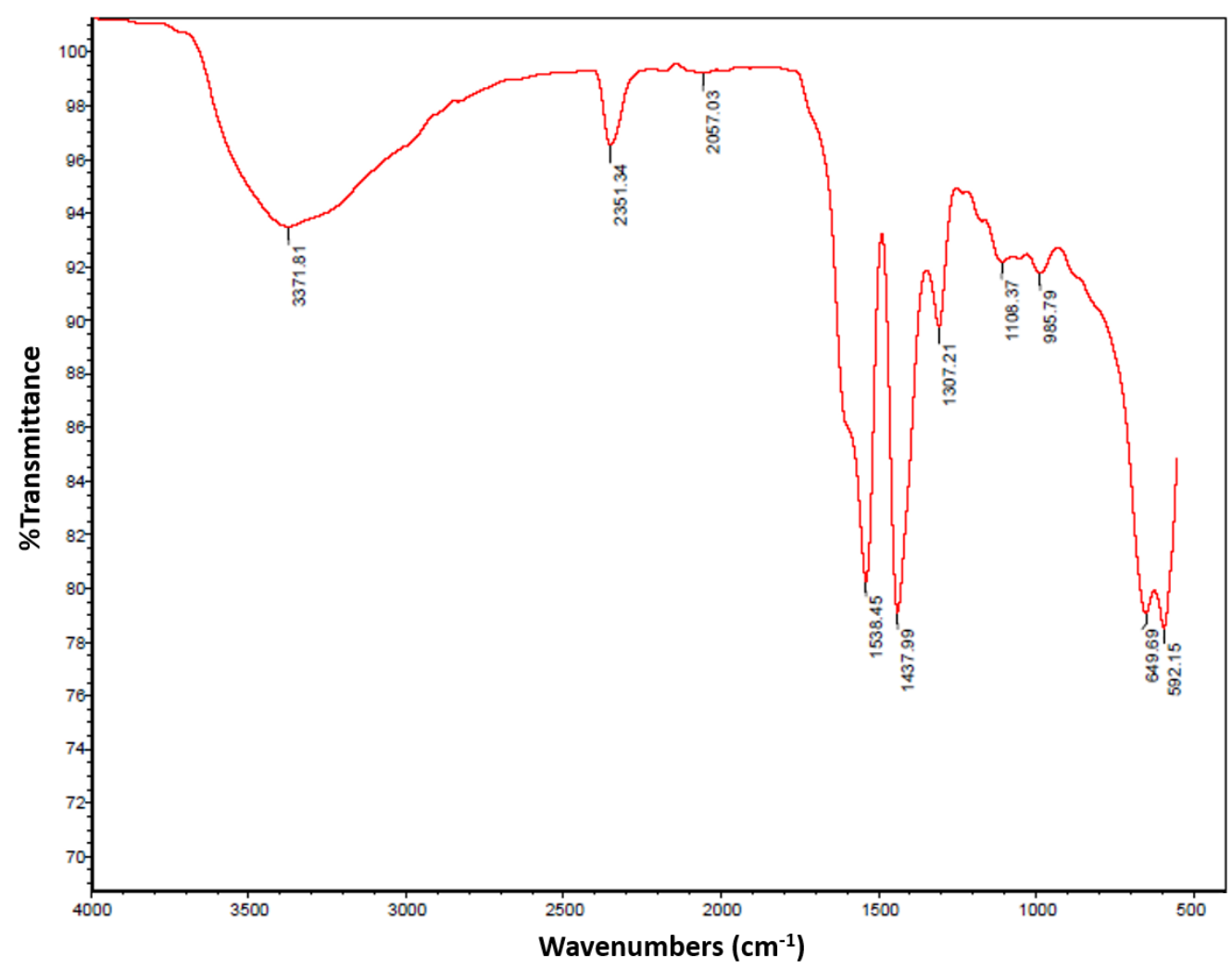

Fig. 2: FTIR spectra of Chromium-Succinate MOFs

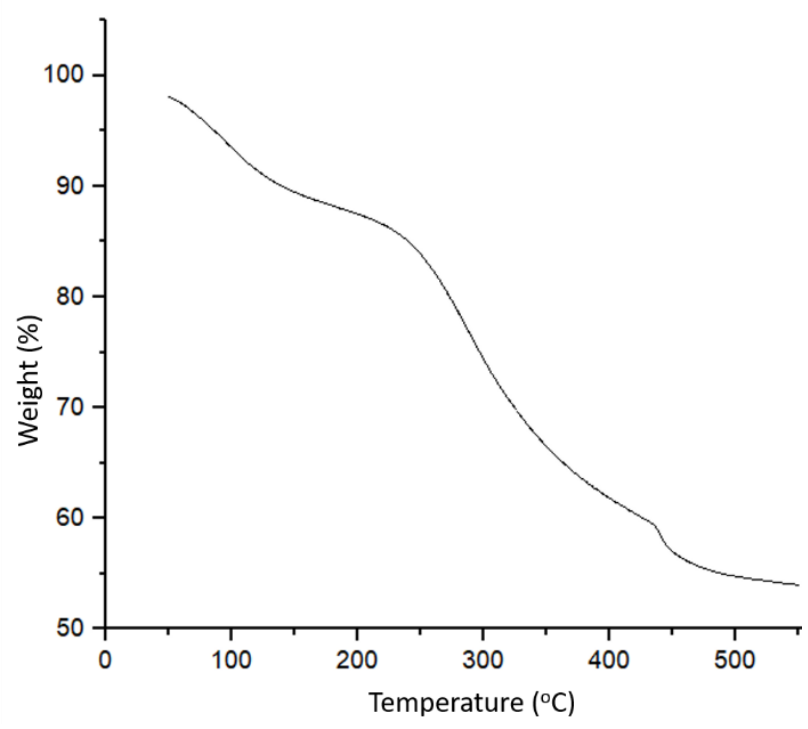

Fig. 3: TG curves of Chromium Succinate synthesized

The decrease in mass that occurred at $250^{\circ} \mathrm{C}$ was due to the evaporation in the MOFs structure. Then, a gradual decline occurred at temperatures above $350^{\circ} \mathrm{C}$ which indicates residues of the $\mathrm{Cr}_{2} \mathrm{O}_{3}$ metal.

\subsection{Morphological Properties}

Bio-MOFs chromium-succinate synthesized was characterized using SEM to see the morphology of the Particle. Fig.4 shows the results of SEM with magnification of 20,000 and 30,000 times. It shows the smooth surface, agglomerates, and pores of Chromium Succinate. EDX characterization was also carried out to know the composition contained in Bio-MOFs that had been synthesized in this study. The composition of adsorbents characterized by EDX can be seen in Table 2 .

Table 2. EDX Result of Chromium-Succinate

\begin{tabular}{|l|l|}
\hline Element & Mass\% \\
\hline $\mathrm{C}$ & 14.75 \\
\hline $\mathrm{O}$ & 13.23 \\
\hline $\mathrm{Na}$ & 1.21 \\
\hline $\mathrm{Cr}$ & 58.11 \\
\hline
\end{tabular}




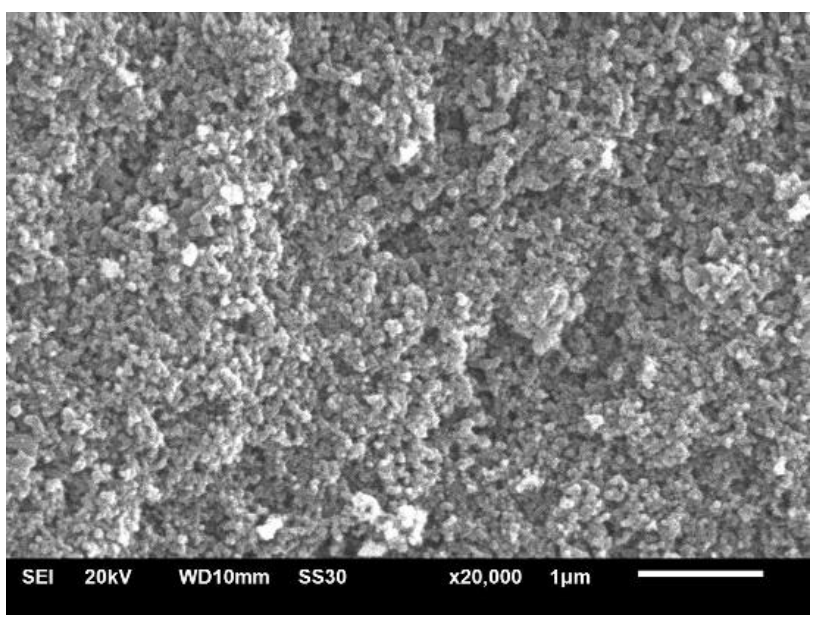

(a)

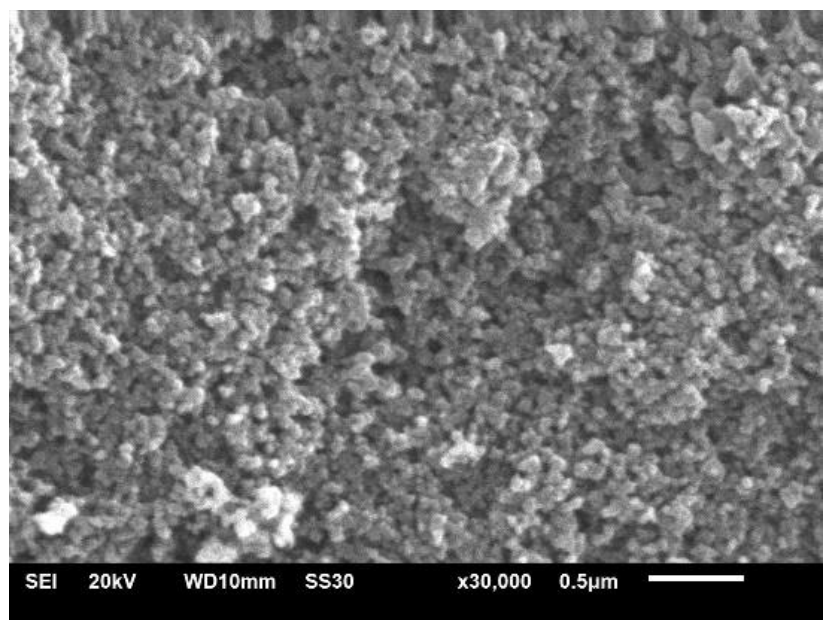

(b)

Fig. 4: SEM images of Chromium Succinate at two different magnifications (a) $\times 20,000$ (b) $\times 30,000$

\section{Conclusion}

We have synthesized Bio-MOFs chromium-succinate through hydrothermal condition in the temperature condition of $160^{\circ} \mathrm{C}$ for 18 hours. It was then characterized for its physical properties using some investigation methods such as FTIR, TGA, SEM, and $\mathrm{N}_{2}$ adsorption/desorption isotherms. In synthesis process, twice purification was performed to remove unreacted substance in the frameworks of MOFs using DMF and hot ethanol. Specific surface area and pore volume obtained are $233 \mathrm{~m}^{2} / \mathrm{g}$ and $0.66 \mathrm{~cm}^{3} / \mathrm{g}$, respectively. The procedure of synthesis of Chromium-Succinate will continue to be optimized to get better porosity and crystallinity. Further, this research could be a starting point in the use of the natural ligand succinic acid in Bio-MOF for $\mathrm{CO}_{2}$ adsorption.

\section{Acknowledgements}

The authors gratefully acknowledge for the Ministry of Research, Technology, and Higher Education, Republic of Indonesia through PMDSU Grant (number NKB-445/UN2.RST/HKP.05.00/2020), the Directorate
General of Customs and Excise of the Republic of Indonesia for the TGA and BET test support, and Osaka Gas Foundation for their financial support.

\section{Reference}

1) D.M. Abouelella, S.-E.K. Fateen, and M.M. Fouad, "Multiscale Modeling Study of the Adsorption of CO_2 Using Different Capture Materials," Evergreen Joint Journal of Novel Carbon Resource Sciences \& Green Asia Strategy, 5 (01) 43-51 (2018).

2) H. Akamine, M. Mitsuhara, and M. Nishida, "Developments of Coal-Fired Power Plants: Microscopy Study of Fe-Ni Based Heat-Resistant Alloy for Efficiency Improvement," Evergreen: joint journal of Novel Carbon Resource Sciences \& Green Asia Strategy, 3 (2) 45-53 (2016).

3) M. Gregg, and M. Newlin, "Global oceans [in "State of the Climate in 2011"]," Bull. Amer. Meteor. Soc, 93 S57-S92 (2012).

4) N.m.A. Lestari, "Reduction of CO_2 Emission by Integrated Biomass Gasification-Solid Oxide Fuel Cell Combined with Heat Recovery and in-situ CO_2 Utilization," (2019).

5) D.M. D'Alessandro, and T. McDonald, "Toward carbon dioxide capture using nanoporous materials," Pure and Applied Chemistry, 83 (1) 57-66 (2010).

6) H. Yang, Z. Xu, M. Fan, R. Gupta, R.B. Slimane, A.E. Bland, and I. Wright, "Progress in carbon dioxide separation and capture: A review," Journal of environmental sciences, 20 (1) 14-27 (2008).

7) C. Kunze, and H. Spliethoff, "Assessment of oxy-fuel, pre-and post-combustion-based carbon capture for future IGCC plants," Applied Energy, 94 109-116 (2012).

8) R. Ben-Mansour, M. Habib, O. Bamidele, M. Basha, N. Qasem, A. Peedikakkal, T. Laoui, and M. Ali, "Carbon capture by physical adsorption: materials, experimental investigations and numerical modeling and simulations-a review," Applied Energy, 161 225-255 (2016).

9) J.-R. Li, Y. Ma, M.C. McCarthy, J. Sculley, J. Yu, H.K. Jeong, P.B. Balbuena, and H.-C. Zhou, "Carbon dioxide capture-related gas adsorption and separation in metal-organic frameworks," Coordination Chemistry Reviews, 255 (15-16) 1791-1823 (2011).

10) D.M. D'Alessandro, B. Smit, and J.R. Long, "Carbon dioxide capture: prospects for new materials," Angewandte Chemie International Edition, 49 (35) 6058-6082 (2010).

11) S. Ishaq, R. Tamime, M.R. Bilad, and A.L. Khan, "Mixed matrix membranes comprising of polysulfone and microporous Bio-MOF-1: Preparation and gas separation properties," Separation and Purification Technology, 210 442-451 (2019).

12) J.M. Plaza, D. Van Wagener, and G.T. Rochelle, "Modeling $\mathrm{CO} 2$ capture with aqueous monoethanolamine," Energy Procedia, 1 (1) 1171 - 
1178 (2009).

13) L. Xu, C.-Y. Xing, D. Ke, L. Chen, Z.-J. Qiu, S.-L. Zeng, B.-J. Li, and S. Zhang, "Amino-Functionalized $\beta$-Cyclodextrin to Construct Green Metal-Organic Framework Materials for $\mathrm{CO} 2$ Capture," ACS Applied Materials \& Interfaces, 12 (2) 3032-3041 (2019).

14) S.L. Anderson, and K.C. Stylianou, "Biologically derived metal organic frameworks," Coordination Chemistry Reviews, 349 102-128 (2017).

15) R.A. Smaldone, R.S. Forgan, H. Furukawa, J.J. Gassensmith, A.M. Slawin, O.M. Yaghi, and J.F. Stoddart, "Metal-organic frameworks from edible natural products," Angewandte Chemie International Edition, 49 (46) 8630-8634 (2010).

16) C. Serre, F. Millange, S. Surblé, and G. Férey, "A route to the synthesis of trivalent transition-metal porous carboxylates with trimeric secondary building units," Angewandte Chemie International Edition, $\mathbf{4 3}$ (46) 6285-6289 (2004).

17) S. Pareek, Nutritional and biochemical composition of lychee (Litchi chinensis Sonn.) cultivars, in Nutritional Composition of Fruit Cultivars. 2016, Elsevier. p. 395-418.

18) Z. Wang, H. Liu, S. Wang, Z. Rao, and Y. Yang, "A luminescent Terbium-Succinate MOF thin film fabricated by electrodeposition for sensing of $\mathrm{Cu} 2+$ in aqueous environment," Sensors and Actuators B: Chemical, 220 779-787 (2015).

19) Y. WU, L. ZHU, H. WANG, W. ZHOU, J. LIU, and M. YANG, "Synthesis of rare earth complexes of $\mathrm{Eu} \sim(3+)$ and $\mathrm{Dy} \sim(3+)$ ions and their luminescent properties," Chemical Research, (1) 7 (2014).

20) R.F. D'Vries, M. Iglesias, N. Snejko, S. AlvarezGarcia, E. Gutiérrez-Puebla, and M.A. Monge, "Mixed lanthanide succinate-sulfate 3D MOFs: catalysts in nitroaromatic reduction reactions and emitting materials," Journal of Materials Chemistry, 22 (3) 1191-1198 (2012).

21) X.-J. Zhang, Y.-H. Xing, Z. Sun, J. Han, Y.-H. Zhang, M.-F. Ge, and S.-Y. Niu, "A series of two-dimensional metal- organic frameworks based on the assembly of rigid and flexible carboxylate-containing mixed ligands with lanthanide metal salts," Crystal growth \& design, 7 (10) 2041-2046 (2007).

22) B.S. Sibnath Kayal, Anutosh Chakraborty, "Study of metal-organic framework MIL-101(Cr) for natural gas (methane) storage and compare with other MOFs (metal-organic framework)," Energy, 772-781 (2015).

23) K.-S. Lin, A.K. Adhikari, C.-N. Ku, C.-L. Chiang, and H. Kuo, "Synthesis and characterization of porous HKUST-1 metal organic frameworks for hydrogen storage," international journal of hydrogen energy, 37 (18) 13865-13871 (2012).

24) B.J. Saikia, and G. Parthasarathy, "Fourier transform infrared spectroscopic characterization of kaolinite from Assam and Meghalaya, Northeastern India," Journal of Modern Physics, 1 (04) 206 (2010).

25) A.S. Chevinli, M. Najafi, and M. Sillanpää, "Removal of La (III) ions from aqueous solution by Lanthanide MOF; characterization, synthesizing and process conditions study," Environmental Nanotechnology, Monitoring \& Management, 12 100216 (2019).

26) B. Seoane, V. Sebastián, C. Téllez, and J. Coronas, "Crystallization in THF: the possibility of one-pot synthesis of mixed matrix membranes containing MOF MIL-68 (Al)," CrystEngComm, 15 (45) 94839490 (2013).

27) P. Roonasi, and A. Holmgren, "A Fourier transform infrared (FTIR) and thermogravimetric analysis (TGA) study of oleate adsorbed on magnetite nanoparticle surface," Applied Surface Science, 255 (11) 5891-5895 (2009).

28) V. Dhanya, M. Sudarsanakumar, S. Suma, S. Prasanna, K.R. Babu, B.S. Kumar, and S.M. Roy, "Growth and characterization of a new polymorph of lead succinate: A promising NLO material," Journal of Crystal Growth, 319 (1) 96-101 (2011).

29) M.a.C. Bernini, N. Snejko, E. Gutierrez-Puebla, E.V. Brusau, G.E. Narda, and M.A.n. Monge, "StructureDirecting and Template Roles of Aromatic Molecules in the Self-Assembly Formation Process of 3D Holmium-Succinate MOFs," Inorganic chemistry, 50 (13) 5958-5968 (2011).

30) J. Miyawaki, J. Yeh, H.-S. Kil, J.-K. Lee, K. Nakabayashi, I. Mochida, and S.-H. Yoon, "Influence of Pore Size and Surface Functionality of Activated Carbons on Adsorption Behaviors of Indole and Amylase," Evergreen: joint journal of Novel Carbon Resource Sciences \& Green Asia Strategy, 3 (2) 17 24 (2016).

31) S.A. FitzGerald, B. Burkholder, M. Friedman, J.B. Hopkins, C.J. Pierce, J.M. Schloss, B. Thompson, and J.L. Rowsell, "Metal-specific interactions of H2 adsorbed within isostructural metal-organic frameworks," Journal of the American Chemical Society, 133 (50) 20310-20318 (2011). 